\title{
The Urine Engine
}

\author{
Yogendra G. Nandagaoli ${ }^{1}$, Rasika R. Kakade ${ }^{2}$ \\ ${ }^{1}$ (Department of Mechanical Engineering, SGBAU, Amravati, India) \\ ${ }^{2}$ (Department of E\&TC, SGBAU, Amravati, India)
}

\begin{abstract}
Nothing is really a waste in the real sense of the word. Almost anything one can think of is reusable. Everything has some value one way or the other. The pollution increases in the world due to carbon monoxide poisoning from fossil-fuel engine, the movement of petroleum products prices, environmental degradation and the recent fuel subsidy scam. So we started looking at different materials, one of which was urine. It is liquid, something that has hydrogen molecules in it. The amount of voltage it takes to break a urine molecule is less than the amount it takes to break the hydrogen molecule in water. So urine electrolyzed, releasing hydrogenoxygen gas mixture from it, then hydrogen gas is purified. The purified hydrogen gas is then pushed into the engine.
\end{abstract}

Keywords: Carbon monoxide, degradation, fossil-fuel, petroleum products, subsidy scam.

\section{INTRODUCTION}

Energy is the very lifeblood of today's society and economy. Our work, leisure, and our economic, social and physical welfare all depend on the sufficient, uninterrupted supply of energy. Yet we take it for granted - and nowadays energy demand continues to increase rapidly, year after year. Traditional fossil energy sources such as oil, coal are ultimately limited and the growing gap between increasing demand and shrinking supply. In the not too distant future we have to be met increasingly from alternative primary energy sources. We must strive to make these more sustainable to avoid the negative impacts of global climate change, the growing risk of supply disruptions, price volatility and air pollution that are associated with today's energy systems. The energy policy of the European Commission advocates securing energy supply while at the same time reducing emissions that are associated with climate change. This calls for immediate actions to promote greenhouse gas emissions-free energy sources such as renewable energy sources, alternative fuels for transport and to increase energy efficiency."The whole fun of living is trying to make something better" said by Charles Kettering, American inventor and social philosopher. Everything has some value one way or the other. Using hydrogen to power cars is an attractive alternative source to fossil fuels because the only hydrogen gas is available in water. But a major problem with this approach is the lack of a cheap, renewable source of the fuel. From the research now we have found the answer in an unexpected place, i.e. our urine.

Although hydrogen is the most abundant element in the universe, on Earth it tends to be locked away in molecules such as water $\left(\mathrm{H}_{2} \mathrm{O}\right)$. To liberate hydrogen gas $\left(\mathrm{H}_{2}\right)$ from water the strong hydrogen-oxygen bonds must be broken. This can be achieved bypassing an electrical current through water (the electrolyte) in a process called electrolysis. However, the energy required forth is process makes it a prohibitively expensive way of making hydrogen fuel. Urine contains urea, $\left(\mathrm{NH}_{2}\right)_{2} \mathrm{CO}$, which has four hydrogen atoms in each molecule. Importantly these are easier to remove than in water because nitrogen-hydrogen bonds are weaker than oxygenhydrogen bonds. During the electrochemical process, pure hydrogen is evolved at the cathode (negative electrode) and nitrogen is collected at the anode (positive electrode). The largest constituent of urine is urea, which is a significant organic source of $\mathrm{H}, \mathrm{C}, \mathrm{O}$, and N. Despite the numerous benefits of using urea/urine for hydrogen production, there is not a single technology that directly converts urea to hydrogen. In addition to sustaining hydrogen resources, such a process could denitrificate urea-rich water that is commonly purged into rivers, creeks, and tributaries from municipal waste water treatment plants. Converting urea to valuable products before it naturally hydrolyzes to ammonia, which generates gas-phase ammonia emissions and contributes to ammonium sulphate and nitrate formation in the atmosphere, will save billions of dollars spent each year on health costs. Here we demonstrate a technology for improving hydrogen resources for energy sustainability by recycling waste materials such as human excreta. As well as producing an environmentally friendly fuel, this process could also be used to clean up waste water. Current methods to remove urine from water are expensive and not efficient. Plans to try and combine the two ideas, so that hydrogen can be collected for use as fuel during the cleanup of effluent from sewage works.

\section{SOURCE OF URINE AND DIVERSION}

Today the alternatives to the conventional wastewater system include systems that separate or urine and faeces in order to utilize the nutrients more efficiently. In regions without piped sewerage, nutrient 
utilization as well as improved sanitation is possible to achieve by avoiding mixing the fractions. If the faecal fraction is kept dry there will be less leaching from e.g. pit latrines and in many places the faeces are also reused. Thus, the two main reasons to separate urine and faeces are to recycle the plant nutrients in urine and to obtain a faecal fraction that is more practical and safer to handle. A number of dry toilets that divert urine from faeces and add-ons to simple dry toilets used in summer houses are also available. There is either a separate flushing mechanism for the urine and faeces or the flush rinses both bowls. The faeces may also be collected dry for composting. The urine is usually collected in a tank placed underground or in a basement under the house. When the tank is full the urine is transported to a farm for later use as a Electrolysis. Before its utilization the urine is stored either in the housing area or near the field. For individual households the urine may also be utilized in the garden directly from the collection tank, without separate storage. Investigations were conducted on both small-scale and large-scale systems.

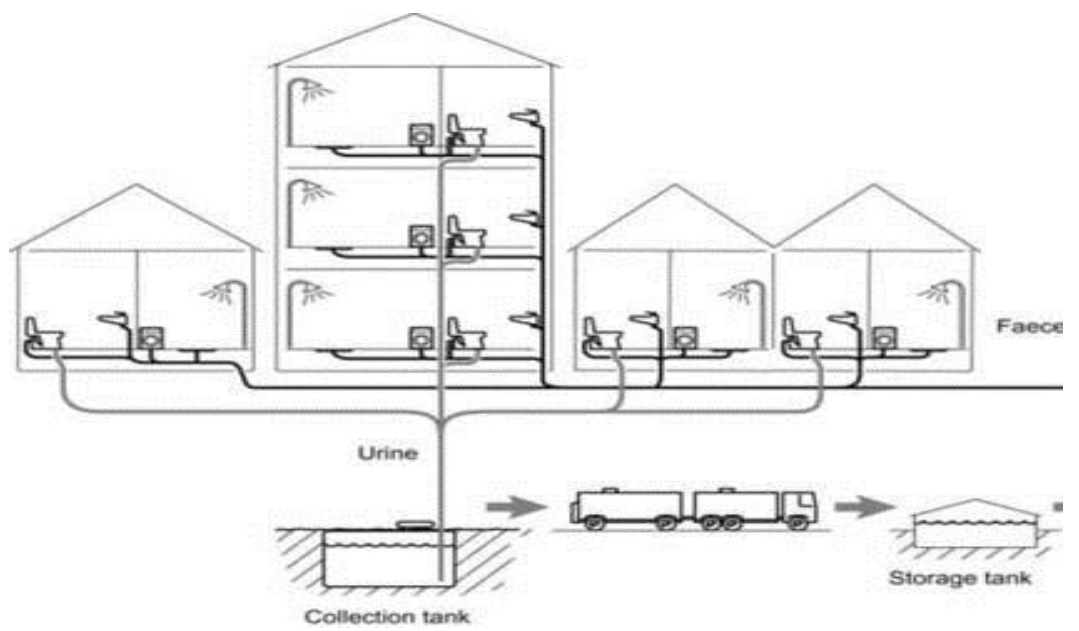

Fig. 1 large-scale urine-separating wastewater system

Facilitating the composting of faeces might be another reason for keeping the liquid separate from the solids. In the Clivus Multrum ${ }^{\mathrm{TM}}$ toilet the urine and leach ate drains to the bottom of the composting chamber where it is collected in a separate tank. This system is manufactured around the world but has been criticized for wasting the urine resource. Another system, the Aquatron ${ }^{\mathrm{TM}}$ can either be connected to a conventional toilet or a urineseparating toilet. Through centrifugal forces the liquid is separated from the solids, which drop down into a composter. The liquid, containing flush water, possibly urine and suspended solids from faecal matter, is treated in an UV-unit and disposed of as grey water. It is worth adding that in order to compost faeces at thermophilic temperatures addition of organic household waste or other material usually is necessary. Ecological sanitation involves treating human excreta as a resource, sanitizing them and then recycling the nutrients contained in the excreta. In developing countries ecological sanitation often refers to a dry system where the urine is diverted from the faeces. The Swedish International Development Cooperation Agency (SIDA) is promoting ecological sanitation including the "don't mix" approach.

\section{Need Of Hydrogen As A Fuel}

A sustainable high quality of life is the basic driver for providing a clean, safe, reliable and secure energy supply in the world. To ensure a competitive economic environment, energy systems must meet the following societal needs at affordable prices:

Mitigate the effects of climate change

- Reduce toxic pollutants, and

- Plan for diminishing reserves of oil.

Failure to meet these needs will have significant negative impacts on

- The economy,

- The environment, and

- Public health.

Measures should therefore be introduced which promote

- More efficient use of energy; and

- Energy supply from a growing proportion of carbon-free sources. 


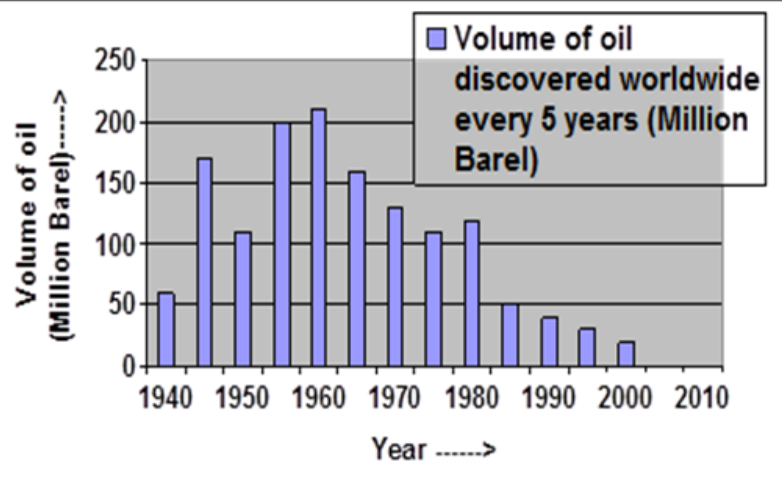

Fig. 2 trend in volume of oil discovered worldwide as per international energy agency's assessment

The potential effects of climate change are very serious and most important of all, irreversible. Electricity and hydrogen together represent one of the most promising ways to achieve pollution free environment complemented by electrolysis of urine which provide very efficient energy conversion. Hydrogen is not a primary energy source like coal and gas. It is an energy carrier. Initially, it will be produced using existing energy systems based on different conventional primary energy carriers and sources. In the longer term, renewable energy sources will become the most important source for the production of hydrogen. Regenerative hydrogen, and hydrogen produced from nuclear sources and fossil-based energy conversion systems with capture, and safe storage (sequestration) of $\mathrm{CO}_{2}$ emissions, are almost completely carbon-free energy pathways. Producing hydrogen in the large quantities necessary for the transport and stationary power markets could become a barrier to progress beyond the initial demonstration phase. If cost and security of supply are dominant considerations, then coal gasification with $\mathrm{CO}_{2}$ sequestration may be of interest for large parts.

\subsection{Properties of Hydrogen}

Auto ignition temperature: $520{ }^{0} \mathrm{C}\left(968{ }^{0} \mathrm{~F}\right)$

Density: $0.08342 \mathrm{~kg} / \mathrm{m}^{3}$

Diffusivity: $1.697 \mathrm{~m}^{2} / \mathrm{hr}$

Flame temperature: $2318{ }^{0} \mathrm{C}\left(4202.4{ }^{0} \mathrm{~F}\right)$

Specific gravity: $0.6960($ air $=1)$

Specific volume: $11.99 \mathrm{~m}^{3} / \mathrm{kg}$ (191.98 scf/lb)

Table 1. Properties of Hydrogen.

\begin{tabular}{|c|c|c|c|c|c|c|c|}
\hline Properties & Gasoline & $\begin{array}{c}\text { Diesel } \\
\text { Fuel }\end{array}$ & Methanol & Ethanol & $\begin{array}{c}\text { Natural Gas } \\
\text { (CNG) }\end{array}$ & Propane & Hydrogen \\
\hline Chemical Formula & $\mathrm{C}_{4}$ to $\mathrm{C}_{12}$ & $\mathrm{C}_{3}$ to $\mathrm{C}_{25}$ & $\mathrm{CH}_{3} \mathrm{OH}$ & $\mathrm{C}_{2} \mathrm{H}_{5} \mathrm{OH}$ & $\mathrm{C}_{3} \mathrm{H}_{8}$ & $\mathrm{CH}_{4}$ & $\mathrm{H}_{2}$ \\
\hline Molecular Weight & $100-105$ & 200 & 32.04 & 46.07 & 44.1 & 16.04 & 2.02 \\
\hline Boiling temp, ${ }^{\circ} \mathrm{F}$ & $80-437$ & $370-650$ & 149 & 172 & -44 & -259 & -423 \\
\hline Octane no & $90-100$ & ------ & 107 & 108 & 112 & ----- & $130+$ \\
\hline Freezing pt ${ }^{\circ} \mathrm{C}$ & -40 & 98 & -115 & -305.8 & -296 & -435 \\
\hline $\begin{array}{c}\text { Flash pt, closed } \\
\text { cup, }{ }^{\circ} \mathrm{F}\end{array}$ & -45 & 165 & 52 & 55 & -100 to -150 & -300 & -- \\
\hline $\begin{array}{c}\text { Auto-ignition temp, } \\
{ }^{\circ} \mathrm{C}\end{array}$ & 257 & $315-460$ & 422 & 422 & $454-510$ & 540 & $565-580$ \\
\hline
\end{tabular}

\section{Methodology}

The system actually consists of an electrolytic cell, water filter, an empty gas can, borax and retarded engine. Urine is placed in the electrolytic cell, where it is electrolyzed and releasing hydrogen-oxygen gas mixture. This mixture then goes into the water filter. The water filter is to remove any impurities that might have come in with the gas and then it goes into an empty gas cylinder which serves as the gas storage. The gas cylinder pushes hydrogen into a cylinder of liquid borax, which is used to remove the moisture from the hydrogen gas. Borax serves as a drying agent and this is because we do not want lots of moisture going into the 
generator. Also, borax helps to remove any other impurities that might have come in with the gas. The purified hydrogen gas is then pushed into the engine. Methodology is mainly divided into three parts.

1. Electrolysis of urine

2. Purification

3. Storing the Hydrogen

\subsection{Electrolysis Of Urine}

An efficient way of producing hydrogen from urine that could not only fuel the cars of the future, but could also help clean up municipal waste water. Using hydrogen to power engine has become an increasingly attractive transportation fuel, as the only emission produced is water - but a major stumbling block is the lack of a cheap, renewable source of the fuel. Using an electrolytic approach to produce hydrogen from urine is the most abundant waste on Earth at a fraction of the cost of producing hydrogen from water. Urine's major constituent is urea, which incorporates four hydrogen atoms per molecule - importantly, less tightly bonded than the hydrogen atoms in water molecules. Electrolysis process is used to break the molecule apart, developing an inexpensive new copper -based electrode to selectively and efficiently oxidize the urea. To break the molecule down, a voltage of $0.38 \mathrm{~V}$ needs to be applied across the cell - much less than the $1.20 \mathrm{~V}$ needed to split water. During the electrochemical process the urea gets adsorbed on to the copper electrode surface, which passes the electrons needed to break up the molecule. Pure hydrogen is evolved at the cathode, while nitrogen plus a trace of oxygen and hydrogen were collected at the anode. While carbon dioxide is generated during the reaction, none is found in the collected gasses as it reacts with the potassium hydroxide in the solution to form potassium carbonate. Urea is oxidized at the anode as shown in above equation at a standard electrode potential of $0.46 \mathrm{~V}$.

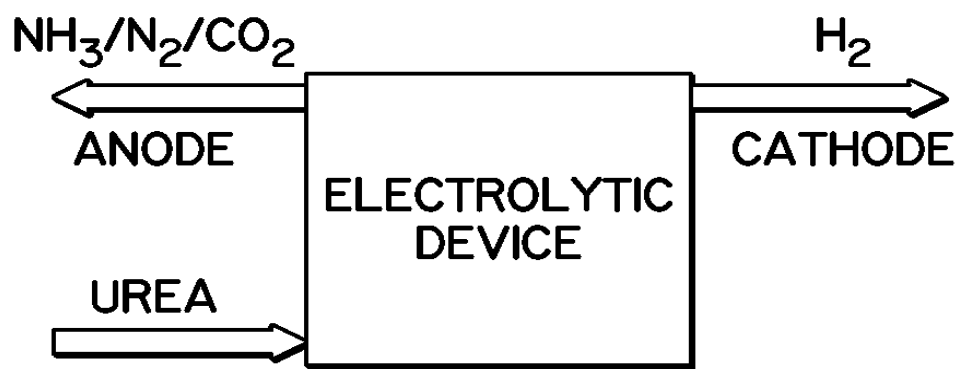

Fig. 3 electrolysis of urine, releasing hydrogen

Nitrogen is generated from the anode demonstrating nitrate remediation of wastewater while water is reduced at the cathode producing valuable hydrogen for the impending hydrogen economy. An electrolytic cell potential of only $0.38 \mathrm{~V}$ is thermodynamically required to electrolyze urea at standard conditions. This is significantly less than the $1.20 \mathrm{~V}$ required electrolyzing water theoretically generating $75 \%$ cheaper hydrogen. Urea naturally hydrolyses into ammonia before generating gas phase ammonia emissions. These emissions lead to the formation of ammonium sulphate and nitrate particulates in the air, which cause a variety of health problems including chronic bronchitis, asthma attacks and premature death.

\subsection{Purification}

The hydrogen gas mixture from the electrolytic cell then goes into the water filter. The water filter is to remove any impurities that might have come in with the gas and then it goes into an empty gas cylinder which serves as the gas storage. The gas cylinder pushes hydrogen into a cylinder of liquid borax, which is used to remove the moisture from the hydrogen gas. Borax serves as a drying agent and this is because we do not want lots of moisture going into the generator. Borax, also known as sodium borate, sodium tetra borate, or disodium tetra borate, is an important boron compound, a mineral, and a salt of boric acid. Powdered borax is white, consisting of soft colorless crystals that dissolve easily in water.

\subsection{Storing of Hydrogen}

Since hydrogen is one of the lightest element and has very small molecules, it an escape from tank and pipe more easily than conventional fuels. However, if it is to be used as a fuel for transport or power generation then there must be used way of storing it cost-effectively. Storing hydrogen can be done in three main ways, compressed from in liquid from and by chemical bonding (i.e. Metal Hydride). A gram of Hydrogen gas occupies about 11 litres (2.9 gallons) of space at atmospheric pressure, so for convenience the gas must be intensely pressurised to several hundred atmospheres and store in the pressure vessel. 
Table 2. Storing of the Hydrogen

\begin{tabular}{|c|c||c|}
\hline Material & H-atoms per $\mathrm{cm}^{3}\left(\mathrm{x} 10^{22}\right)$ & \% of weight that is Hydrogen \\
\hline \hline $\mathrm{H}_{2}$ gas, 200 bar $(2850 \mathrm{psi})$ & 0.99 & 100 \\
\hline $\mathrm{H}_{2}$ liquid, $20 \mathrm{~K}\left(-253^{\circ} \mathrm{C}\right)$ & 4.2 & 100 \\
\hline $\mathrm{H}_{2}$ solid, $4.2 \mathrm{~K}\left(-269^{\circ} \mathrm{C}\right)$ & 5.3 & 100 \\
\hline $\mathbf{M g H}_{2}$ & 6.5 & 3.6 \\
\hline \hline $\mathbf{M g}_{2} \mathbf{N i H}_{4}$ & 5.9 & 1.89 \\
\hline \hline $\mathbf{F e T i H}_{2}$ & 6.0 & 1.37 \\
\hline
\end{tabular}

\section{Wankel Engine}

Two German engineers Felix Wankel and Walter Filter have developed the rotary engine which is known as Wankel engine.

\subsection{Glossary of Terms}

Apex : One of the three tips of the rotor.

Eccentric Shaft : the rotors move around it. It has sections that are offset from the centre. It super cedes the crankshaft of piston engine.

Epitrochoid : The curve that defines the inner surface of the peripheral housing is called as epitrochoide. It is generated by rolling a circle around another circle. Perhaps should more correctly called peritrochoid .

Rotor : The rotor is the part of the engine that receives the power impulse of the explosion and combustion of the fuel air mixture. It super cedes the piston of old internal combustion engines. It sometimes loosely called a "rotary piston" Epitrochoid curve generation method

Stationary Gear : This gear is fixed to the side housing. It meshes with a gear inside the rotor so that the motion of the rotor is constrained.

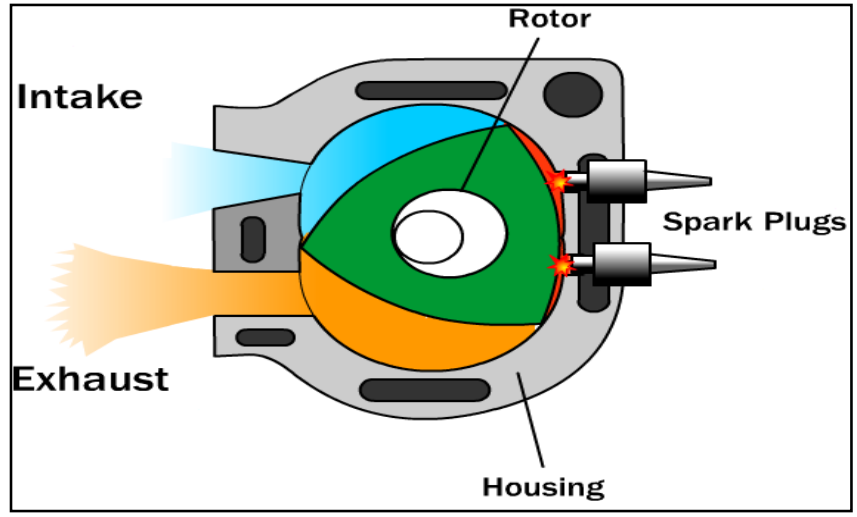

\subsection{WORKING OF WANKEL ENGINE}

Fig.4 wankel engine

Construction \& working of Wankel Rotary engine is as in figure 4.Rotor having eqilaterateral triangular shape rotates in lobe shaped chamber as well as revolve on eccentric shaft. As rotor rotates volume enclose between Rotor and chamber decreases and increases uniformly according to its position, which causes compression and expansion of the charge. As 3 chamber are formed on 3 sides of rotor we get 3 expansion or power stroke for 1 revolution of rotor .There are 3 revolution of eccentric shaft i.e. output shaft. Thus we get 1 power stroke for each revolution of output shaft. Internal gear of Rotor meshes with external gear, which is fixed to casing of engine, which regulates the motion of Rotor to maintain contact between rotor and casing. Each phase of thermodynamic cycle occur for $90^{\circ}$ revolution of rotor, those for $270^{\circ}$ revolution of output shaft.

\section{CONCLUSION}

The energy is required for urea electrolysis is $35 \%$ less, which generated $40 \%$ cheaper hydrogen compared to water electrolysis. For this system, the exhaust gas is the water vapour. It does not emit carbon monoxide like the normal fuel-based engine so this ensures clean environment for people. Again, one litter of urine can give you six hours of electricity. The source of urine is naturally available from human being and cattle so there is availability of hydrogen easily. Using an electrolytic approach to produce hydrogen from urine is the most abundant waste on Earth at a fraction of the cost of producing hydrogen from water. The hydrogen 
gas gives many more application in all the fields such as in cars, vehicle and also used to burned either to provide heat. But it required special arrangement. It is used to drive turbine, in internal combustion engines for motive and electrical power. Urea naturally hydrolyses into ammonia before generating gas phase ammonia emissions. These emissions lead to the formation of ammonium sulphate and nitrate particulates in the air, which cause a variety of health problems including chronic bronchitis, asthma attacks and premature death.

\section{Acknowledgements}

Foremost, we would like to express our sincere gratitude to Mr. Sagar Jirapure for his continuous support, patience, motivation, enthusiasm and immense knowledge. His invaluable guidance helped us a lot. Besides him we would like to thank our faculties, lab technicians and our respected HOD for their valuable advices and their significant contribution. The product of this research paper would not be possible without all of them.

\section{REFERENCES}

[1.] Bryan K. Boggs, Rebecca L. King and Gerardine G. Botte" Urea electrolysis: direct hydrogen production from urine" 11 th June 2009

[2.] Duro-Aina Adebola, Bello Eniola, Akindele Abiola and Faleke Oluwatoyin "Generatation of electricity from urine "February 14, 2013.

[3.] Dr Gerardine Botte"Hydrogen Fuel from Urine" September 2009.

[4.] Mathur M. L. , Sharma R. P., 'A Course in Internal Combustion Engines', "The Wankel Rotary Combustion Engine", Ch. 23, Pg. No. 822 Dhanpat Rai and Sons publication, New Delhi.,1992.

[5.] Prof. Khajuria P. R, "Hydrogen-Fueled Spark Ignition Engine-Its Performance and Emission Characteristics", Ph. D. Thesis, I. I. T., New Delhi., July 1981.

[6.] H. J. Plass, F. Basrbir "Economics of hydrogen as a Fuel for Surface Transportation" S.A.E. journal, Pg. No. $363-368$. 